\title{
Gender and Generation in Swedish School Radio Broadcasts in the 1930s:: An Exploratory Case Study
}

Anne-Li Lindgren

\section{Linköping University Post Print}

N.B.: When citing this work, cite the original article.

Original Publication:

Anne-Li Lindgren, Gender and Generation in Swedish School Radio Broadcasts in the 1930s:: An Exploratory Case Study, 2012, Journal of the History of Childhood and Youth, (5), 2, 239-259.

http://dx.doi.org/10.1353/hcy.2012.0017

Copyright: John Hopkins University Press

Postprint available at: Linköping University Electronic Press

http://urn.kb.se/resolve?urn=urn:nbn:se:liu:diva-77760 


\section{Gender and Generation in Swedish School Radio Broadcasts in the 1930s: An Exploratory Case Study}

Anne-Li Lindgren

\section{INTRODUCTION}

The radio broadcasts examined here belong to the documentary genre and as such form part of a European, Canadian, and American movement emphasizing documentary films, literature, and radio as tools of the emerging welfare state. The "New Deal" and "social realism" were buzzwords in this discourse. ${ }^{1}$ Although few studies focus on dialogues in radio programs, particularly with regard to educational radio, David Hogarth argues, in an article about radio in Canada starting in the 1920s, that private radio stations brought "real life" into the everyday lives of Canadians in new ways. ${ }^{2}$ Features of documentaries, such as sound effects, a personal style of address, and coverage of events where and when they happened, were consciously used to create a sense of immediacy and actuality. Such features had a huge impact on early broadcasting and particularly on information programs. As early as the mid 1930s, documentary programming had become "a uniquely educational, entertaining and efficient way of telling stories about the nation."3

Hogarth's findings serve as important background to understanding the Swedish radio dialogues studied here. In general, school broadcasts embodied the documentary features mentioned above, but in a different organizational setting: a centralized, public, monopoly corporation, i.e., the Swedish Broadcasting Corporation. ${ }^{4}$ This article proposes a method for studying historical radio dialogues with participating children and, in doing so, presents early examples of the participation of ordinary people in the medium. This proposed in-depth method focuses on the interaction in the dialogues in order to gain an understanding of discursive change from a historical perspective and, more specifically, of how radio dialogues can be understood as sites for negotiating citizenship norms and values. The focus is on changed notions of gender and generation; the staring point is critical discourse analysis, but as applied to historical material and adapted to radio dialogues. The argument put forward is that the presented method can improve our understanding of how notions of gender and generation have been challenged in everyday practices, here, in the form of everyday radio dialogues with participating children. The programs themselves contributed to and were part of societal change, 
and, at a micro level, the analysis improves our understanding of how changes occur at a structural level, i.e., that of society.

\section{Nationwide broadcasts and teacher involvement}

The School Radio broadcasts were initially intended as a pedagogical tool for improving upper secondary school education, mainly in foreign languages, but teachers resisted the idea. Instead, they were launched for "compulsory school" (i.e., elementary and secondary school), where teachers embraced the initiative, and in 1931 a special department for School Radio was organized at the Swedish Broadcasting Corporation (SBC). ${ }^{5}$ SBC was founded in 1925, and was broadcasting nationwide under a license from the government. Commercial radio stations were taken over by SBC or forced to close down. SBC chose a broadcasting model known from other western European countries, including Britain and Germany, and in Sweden the emphasis on "public service" was essential. ${ }^{6}$ The department for School Radio took a special interest in educational broadcasting by BBC in England and DRK in Denmark. ${ }^{7}$ Funding came from special fees paid by radio owners, and advertising was not allowed.

As a new technology, radio, like the movies, attracted a mass audience of all ages and with diverse socio-economic backgrounds. In contrast to America, issues of censorship for the protection of children were never raised in Sweden, which might be explained by the strong influence of the idea of the public service mission and by the absence of advertising and commercial actors in the Swedish radio broadcast system.

Being part of the SBC meant that School Radio was an administrative unit of the general broadcast organization, even though the Ministry of Education and Ecclesiastical Affairs as well as the Board of Education contributed funding during the test period. ${ }^{8}$ A program was broadcast nationwide, creating what Benedict Anderson refers to as an "imagined community,"9 and it was only the presentation and the time slot that signaled the educational mission to the audience. Each broadcast lasted approximately 20-40 minutes and reached people in their homes, as well as students (7-13 years old), just after lunchtime several days a week in the spring and autumn terms. Schoolchildren were supposed to have an instruction manual containing a short summary of each program, photographs, pictures, and questions to be discussed afterwards. The manuals were distributed to 
schools for free at the beginning of each term and the Swedish Board of Education performed a preliminary examination of the manuals — but not the broadcasts— before they were sent out. ${ }^{10}$ In the School Radio organization it was emphasized that to change how people thought about society, one needed to change how they talked. Images produced by pictures and images produced by language ("hearing pictures") were important in that process, and the instruction manuals were supposed to maintain and sustain that process. ${ }^{11}$

In communities throughout Sweden, teachers participated in ongoing surveys in which they reported their own and their students' responses to the School Radio programs, and were occasionally given the opportunity to produce programs. ${ }^{12}$ When producing programs, the teachers influenced both their content and form; teachers preferred subjects related to society, dialogues, and current events reportage. This form of teacher engagement can probably explain why School Radio became a success in Sweden. It combined a top-down organization with initiatives from the main target group, the compulsory school teachers. ${ }^{13}$ As Larry Cuban has pointed out, in America, teachers were not involved in program production and hence never became involved in integrating radio into education. ${ }^{14}$

In research into Swedish school broadcasting, the top-down perspective has so far been central, emphasizing the role of the educated elite, experts and professionals, as well as the patriarchal tone of address, in the broadcasts. ${ }^{15}$ In addition, this article highlights broadcasts that were part of the everyday experience of teachers and children in school. Instead of concentrating on well-established and well-known radio producers, the present case study examines programs produced by ordinary teachers or representatives of civic organizations. ${ }^{16}$ Moreover, the in-depth analysis presented here goes beyond merely analyzing the topics of the programs, going into detail concerning the format and content of the broadcasts. The analysis highlights the perspective of the ordinary — an important aspect of the documentary genre, and particularly emphasized in television. Graeme Turner refers to the "demotic turn" he claims came about in the 1990s. ${ }^{17}$ Turner, and others emphasizing the historical perspective on broadcasting, point to the demotic as a central function of commercial media systems interested in consumer culture, entertainment as seduction, and desire for liberation and functioning as producers of cultural identities. ${ }^{18}$ 
This article provides examples of how the demotic has played an important role in the production of cultural identities as well as in nation-state discourses aiming at making citizens, i.e., providing information to the public to enable the functioning of a democratic state. This article highlights how democratic discourse, rooted in education and existing outside the commercial market, used the participation of ordinary people as a way to attract and motivate the audience.

\section{New media as a forum for new ideas}

As Maija Runcis and Bengt Sandin point out in a study of educational broadcasting (radio and television) in Sweden from 1930 to 2000, Swedish radio initially aimed to be a public service informing and improving the general public. To accomplish this mission, from the outset, SBC had to work with non-governmental organizations, governmental agencies, and other institutions and organizations. In fact, radio broadcasting created a new public arena, accessible to a variety of interests, in which spokespeople for the state and civil society were given voice side by side.

Educational broadcasting had a privileged position because of its intimate connection to education and thus welfare policy. As Runcis and Sandin carefully point out, in Sweden, "school broadcasting and educational broadcasting were flanked by the relevant government bodies and the educational system on the one side, and interested members of the public and non-government organizations on the other, with radio as the connecting thread." ${ }^{19}$ Runcis and Sandin also identify the unique role educational media played in relation to political and social change, a role ignored by the formal educational system. $^{20}$

The School Radio concept was outlined early on, and by 1935 production had become organized and regular. The content of School Radio programs was generally in line with the overall curriculum, though they generally portrayed the state in a new light, i.e., as a fair and caring mother who sees to the wellbeing of all family members. This was particularly obvious regarding the then new subject of citizenship. Reoccurring topics concerned the everyday lives of the working or lowermiddle classes as well as the need for health reform and an expanded welfare system. Notably, lectures on the advantages of paying taxes were given by a Social Democrat-appointed Head of the Department of Education. Other programs promoted an understanding of the nation as involved in a modernization process based on technological development; these included school broadcasts about ideal homes 
provided with electricity, safety devices, and modern living conditions or about new flight paths, or construction projects for roads, or underwater tunnels. This was at a time when the Social Democrats had not yet achieved the leading political position they would have in the future, but were party to a coalition. Being in Sweden in the 1930s, meant taking part in democratization in which progressive notions of citizenship challenged traditional ones, as exemplified by the above School Radio topics. As in periods of radicalization, children were used as symbols of the future in this process, ${ }^{21}$ and this article argues that children were assigned active roles in mediating this discursive change by participating in the new national medium, but in an educational context.

The radio programs, available as scripts stored in the SRF Research and Archive Center in Stockholm (SRF), have been studied as texts, which is in line with CDA. ${ }^{22}$ The scripts were written in advance of the broadcasts by adults and performed live by adults and children. It was emphasized that the participants should follow the written text. The scripts were written as dialogues, using the style and conventions of oral language. Oral style was used in the broadcasts for two reasons: 1) it increased the sense of authenticity, suggesting, for example, that the participants were on location and not in a studio (which they were), and 2) it was a strategy for teaching citizens "how to talk" using good oral style, in contrast to the written style of language taught in school textbooks. Contemporary notions of active civil engagement in Sweden implied participation, for example, in public debates. To be an informed voter, an engaged citizen at democratic political meetings and active in social gatherings and cultural events, one needed to master oral language. The argument was that since children did not learn to use proper spoken language in school, they could not become engaged citizens. Being a new verbal medium without traditional forms constraining choices of topics and content, School Radio was regarded as an important tool in creating modern civil engagement. ${ }^{23}$

Swedish School Radio allowed the use of uneducated speakers, and essentially ignored listener complaints about provincial dialects or grammatical errors. School Radio also supported the idea of dialogues in which real people performed "clips of actuality" instead of one-voice lectures or monologues. The most important skill emphasized in the broadcasts was the ability to talk to students ${ }^{24}$ — clearly a strategy for attracting listening teachers and students in school, and not the general public. In this, Swedish School Radio was more wholehearted in embracing demotic speech 
and hence was more progressively minded than the $\mathrm{BBC},{ }^{25}$ and was probably more progressive than general Swedish Radio, SBC.

A case study: material, theory, and method

In 1935, 69 broadcasts were produced for elementary schools, including sixteen programs in which children participated. The present article makes a case study of five of them: Among sacks of fertilizer and sacks of seed in a farmers' association (9 January) (Olof Berg), Small bad habits—big money (23 January) (Unknown), The calendar-our most widely distributed reference book (21 February) (Lorentz Larsson), The tone of voice (14 March) (Ebba Berggren), and How to use the telephone book (21 March) (Karin Skerfe). It should be emphasized, however, that the case study also refers to the structure and content of all sixteen programs involving children, and to other dialogues of the 69 involving only adults.

The five case study programs were singled out for two main reasons, the first concerning program content. The topics treated in the five programs relate to: the idea of democratization outlined in the section above, how and where people ought to live, food production and management, the organization of youth in society, and how to learn to use new technology and, in a general sense, orient oneself in a modernizing world (here exemplified by a calendar). In addressing these topics, the broadcasts related directly to crucial issues in a Swedish society preoccupied with democratization and, in addition, to the issue of demotic speech in radio.

The constellations of children and adults participating in them were the other main reason for choosing these five programs. The few female producers of these programs used women and girls in them, while the male producers used men, girls, and boys. Of the two programs produced by women, one used one woman and one girl, and the other used two girls and a woman. Of the three programs produced by men, one used a man, two boys, and a girl; one a man, a boy, and a girl; and one a man, a boy, a girl, and unspecified classmates.

In CDA, everyday practices — not structures — are the objects of study and form the basis for conclusions about social relations, continuity, and change. Such practices are regarded as potent enough to affect structures, and therefore are of major analytical interest, even though there is a dialectical relationship between practice and structure. Structures are reproduced but also transformed 
by discursive practices. ${ }^{26}$ In the present article, dialogues in radio programs are treated as discursive practices. Historical material is thus being studied in light of a theory and method originally designed for contemporary material, which means that care must be exercised when drawing conclusions. In performing the analysis, knowledge of contemporary ideas concerning the societal context of the broadcasts, for example, education, progressivism, civic engagement, and citizenship, were particularly important. Contemporary teachers' publications, state inquiries, and media debates were used to understand the meanings presented in the examined educational radio programs.

The five selected programs serve as the basis for a case study in which discourse analysis of everyday interactions is performed on historical material, here, radio dialogues. The method focuses on the features of a conversation that, according to CDA, highlight interactional control, that is, power relations and negotiations between participants. The interactional control features chosen for this case are choice of topic (what the participants talk about), turn-taking (who is given the authority to talk), and the distribution of questions and answers in the dialogues. A conversation involves other utterances than just questions and answers, and these have here been categorized as statements. This means that all questions, answers, and what I have chosen to call statements have been counted in the programs. Each category has been related to the people delivering the constituent questions, answers, or statements. The results are presented in Table 1 below.

Table 1. Questions, answers, and statements in five school radio broadcasts in 1935. [Should be inserted somewhere here]

The next step in the analytical process was to identify who directed or answered a question, and when questions were posed or answered without directives. This gives indications of who controlled the topic and turn-taking in the conversation. Controlling the choice of topic, turntaking, and questioning, and being able to provide answers, were interpreted as leading to a position of power in a conversation. ${ }^{27}$ In this way, the article discusses the various ways interactional control in radio dialogues can be interpreted, paying special attention to gender and generational issues in an educational context. The case study thus explores how this method offers a new way to understand how notions of citizenship are produced and mediated in everyday media practices. 
The programs have been analyzed as producers of discourse in public media, more specifically, as producers of positions adults and children can assume or use in their everyday lives. As documentaries, the programs were presented as true records of how schoolchildren and adults were supposed to behave. Since the manuscripts were written by adults before the broadcasts, they clearly represented discursive positions presented and supported by adults. The analysis identifies the discursive positions presented as examples for the listening children and adults, regardless of whether or not they represented actual life. It is an important starting point of the analysis that the programs were presented as "real" events from everyday life, even though this was of course not the case; nevertheless, it is as "real events" that the dialogues have been analyzed.

\section{GENERATIONAL BOUNDARY WORK}

In undertaking critical discourse analysis of the dialogues, the distribution of questions and answers can be considered as articulating pedagogical values and generational boundary work. In the following script concerning how to use the calendar, both these issues are relevant. Lorentz Larsson's The calendar - our most widely distributed reference book (1935) was presented as an ordinary school lesson involving a male teacher in dialogue with a female and a male student. The dialogue started with a discussion between the two students without teacher involvement. However, after some time spent discussing the price of a stamp, the discussion became agitated and antagonistic. The teacher then entered the scene and obviously had three tasks to accomplish: end the agitated discussion, provide an answer (the price of a stamp), and teach students and radio listeners how to use the calendar:

\section{Script 1.}

(1) TEACHER: Okay, how are we going to end this argument? Yes, one way would be to go to the post office and ask, but that's quite complicated. You might remember, this autumn you heard a woman teacher and some children on the radio who were talking about books one can use to find all kinds of information. INGVALL and ANN-MARIE: Those are reference books.

TEACHER: That's correct. There were several of them. Do you remember the name of the biggest one? INGVALL and ANN-MARIE: The Nordic Family Book.

TEACHER: How many volumes? 
INGVALL: Thirty-eight.

TEACHER: And they're thick, so you understand they're expensive. They cost hundreds of Swedish crowns. Not many can afford to buy such books, but there's a reference book that's so cheap every man, even every boy and girl, can afford it. Do you know what that is?

(2a) INGVALL and ANN-MARIE: [silence]

TEACHER: Well, if you think about it, it costs 25 öre [Swedish cents]

(2b) INGVALL and ANN-MARIE: [silence]

TEACHER: You don't [know?] Look here, this is what it looks like.

(3) INGVALL and ANN-MARIE: Ooohhh! The calendar!

TEACHER: Yes, it's an excellent reference book. Even though it doesn't include as much information as the Nordic Family Book, it does have a great deal. What do you use the calendar for, Ann-Marie?

(4a) ANN-MARIE: To see what day it is.

TEACHER: And you Ingvall?

(4b) INGVALL: To find out what date it is.

TEACHER: Yes, that's good, but there are many more facts written in the calendar. We'll see what we can find when we look into it. ${ }^{28}$

This is the script of a broadcast in which an adult posed questions and students provided answers. Each question could be answered with a single fact, and the adult posing the questions already knew the answers, indicating that this was a kind of test. However, there were different expectations for the first and last questions. At the beginning, the adult explicitly referred to an earlier pedagogical situation in which the students had been able to provide answers (see 1). In the second part, the adult guided the students by referring to everyday life outside the pedagogical context. In this case, the students were not successful (see $2 \mathrm{a}$ and $2 \mathrm{~b}$ ). Despite being given several leads, they were unable to answer. When the answer was presented to them by the teacher, its simplicity was shown by the students' reaction, indicating that the answer was actually quite obvious (see 3).

In relation to the ideals propagated in the new education of the time, that school and society ought to reflect each other's practices, ${ }^{29}$ the script can be interpreted as a critique of contemporary elementary schooling. The students' performance actually displayed, in a public medium, the problems of contemporary schooling. The students were able to answer school-related 
questions, but were unable to draw on everyday experiences in a pedagogical context. This means that the students were unable to bring society into school. At the end, after the adult had provided the answer, the students put this ideal into practice. The boy and the girl had clearly used calendars in their lives outside school, and thus could come up with some answers (see $4 \mathrm{a}$ and $4 \mathrm{~b}$ ). One conclusion is that the broadcast advocated progressive ideals in line with the new education in two ways: first, by revealing the inadequacies of contemporary compulsory schooling, and second, by having students serve as role models in showing how schools ought to work. Taken together, these two perspectives argue strongly for the advantages of the new education, while presenting "factual" examples of such practices.

On the other hand, when focusing on the generational boundary work in the analysis, the progressive ideal was downplayed. Despite indirect references to the new education, the teacher was positioned in an asymmetrical power relationship, with a higher status than that of the students. Several features placed the teacher in a high-status position (see script 1 above): 1) the teacher knew the answer and tried to guide the students to it, 2) the teacher first defined the good qualities of the calendar and, in a second step, asked for the students' opinions, and 3) the students' responses were acknowledged, but did not influence the rest of the dialogue, meaning the students could not choose the topic. Instead, the teacher always chose the topic, thereby controlling the dialogue. The students never posed questions or directed any talk toward the teacher. Moreover, when the boy and girl interacted at the beginning of the program, they were positioned as opponents. When the adult entered the dialogue, he resolved the children's conflict, giving the impression that they depended on his intervention. Thus, the children were not portrayed as sharing an interest, but instead as divided and as having different interests. These aspects were typical not only of the script above, but of the entire program.

The analysis clearly demonstrates new pedagogical ideals being put into practice, while upholding traditional power relations between the generations. The following examples will illustrate how traditional representations of generational boundaries could be challenged in the series.

In another program, Ebba Berggren's The tone of voice (1935), the distribution of questions and answers was more ambivalent with regard to the positioning of the adult and child. A 
female teacher made a program about how to talk using proper spoken language — in contrast to written language taught from textbooks. Much like other programs, the adult asked the girl test questions. In this program, in contrast to the program about the calendar, the girl also asked the adult several questions, in this way, choosing the topic and partly controlling the topic of conversation. However, the girl's questions were different from those posed by the adult. The girl did not know beforehand what the answers were, so her questions were not test questions, but instead aimed to obtain expert advice from the adult. ${ }^{30}$ This positioned the adult as a kind of expert, while placing the child in a position similar to that of teachers in programs involving only adult participants. In programs in which adults were in dialogue, one common strategy was to let the teacher be a kind of interpreter between the expert and schoolchildren, a role in which the teacher posed questions regarded as relevant to the students' level of knowledge. ${ }^{31}$ Thus, compared with the dialogues in programs involving only adults, this girl was given a position somewhat similar to that of the male teachers. She performed a kind of adult behavior, thereby transgressing presuppositions about her expected position as a girl or student.

In programs involving only adult participants, male teachers often assumed the role of ideal active citizen, educating themselves about Sweden's modernization process and development. For example, teachers might interview a civil servant or engineer about regulations or technical devices such as refrigerators, irons, switches and cords, and cars or about how to build safe roads. In these dialogues, male teachers repeatedly referred to the everyday environment of ordinary citizens and schoolchildren, while experts such as engineers referred to authorities, laws, and the government (which guaranteed quality by conducting inspections). ${ }^{32}$ I wish to argue that the child, more specifically, the girl, was positioned similarly in the program The tone of voice, thereby performing active citizenship, where "manly" behavior was the norm, in a public medium. That the generational order could be challenged becomes even clearer in the next example.

\section{GIRLS WITH A SELF-DEFINED INTEREST IN LEARNING}

Karin Skerfe's How to use the telephone book (1935) stood out in the series because most of the dialogue occurred between the students (two girls). As in programs involving only adults, the dialogue was characterized by statements rather than by questions and answers. The girls controlled the topic of 
conversation and thereby the content themselves. The dialogue, in which they are searching for information in the phone book, established a distinction between the girls. Märta repeatedly suggests that they should ask for the teacher's help. Ebba, on the other hand, responds to this request using various strategies, wanting them to solve the problems themselves. Putting this difference on display in the dialogue explicitly communicates ideals concerning student initiative. Despite their different approaches, but thanks to their joint collaboration, the girls arrive at one conclusion after another. This is exemplified in the following script:

\section{Script 2.}

MÄRTA: What? May I see? Carlsson, Carlsson look at Karlsson [i.e., Swedish surname]! What does that mean? I don't understand this either. Should we ask the teacher about it?

EBBA: No, not yet. It's so annoying, showing that one doesn't understand immediately. May I borrow the book again? Carlsson, Carlsson look at Karlsson—now I know Märta, look and I'll show you. The first Carlsson begins with a $C$ and the last one with a $K$. Look, it's written Karlsson! One must look it up under $K$, and then all Karlssons who own a telephone are listed there.

MÄRTA: Well, that might be true. So it was not so silly of me to look up $K$ before. But look again Ebba, it's written Carlsson with $C$ twice here. Why is it like that?

EBBA: That's funny! May I see? Yes, it is. Could it be a misprint?

MÄRTA: It can't be a misprint if it's in the telephone book, you must understand. No, but we'll look at them very carefully. Now I can see. The first Carlson only has one $s$, but the other has two. Don't you think it's like this, that even though they're spelled differently, they're written in the same place as those Karlssons who spell their names like they sound?

EBBA: This is tricky. But it makes sense after all. Because when one looks for something in the telephone book, one doesn't think about how it is spelled. After all, one can't know that unless one has already seen it in writing.

MÄRTA: Yes, that's for sure! I can't understand why we didn't think of that before! Some people spell their names in all kinds of strange ways. In a printed book, I once saw Erixon with an $x$ instead of $k s$. That was convenient for sure. ${ }^{33}$

The girls' initiative and collaboration were elaborated on throughout the program. Another aspect of this program is that it shows children in the same kinds of equal positions as adults 
were given in the programs involving only adults. These girls were not portrayed as in conflict, and the questions, answers, and statements were equally distributed between them (see Table 1).

One of the girls was specifically described as a self-assured, autonomous individual who endeavored to solve problems without the help of adults. The producer had Ebba express her selfreliance explicitly:

\section{Script 3.}

EBBA: Hurray, we're so excellent!

MÄRTA: Stop blowing your own horn! Think about how long it took before we arrived at the conclusion.

EBBA: Yes, that's true, but we did it on our own!

MÄRTA: I'll write this down, so we can show it to the teacher.

EBBA: This was fun. Can’t we discover anything else? ${ }^{34}$

As shown in the script, Ebba says that the school task was fun, and that she wants to do more tasks as well. It seems plausible to interpret this as an expression of the producer's notion of the ideal student: possessing initiative and with a self-defined interest in learning. One indirect message was that the reward the capable student can expect is a positive apprehension of him/herself and his/her abilities, as opposed to striving for the teacher's approval. This was the most significant example of the ideal, initiative-taking student in this year's series, and it featured a girl.

When the teacher finally came on the program, she did pose test questions, but was also supportive, constantly praising the girls' efforts. Moreover, she used a jovial tone, indicating that she and the girls were of equal status. In addition, when the girls showed themselves to be more informed about the telephone book than their teacher was, this emphasized the equal status of the adults and students. In the broadcast, one girl discovered that when it was hard to catch the spelling, one could use names instead of letters, for example, Sven for $S$ and Olle for $O$. This was a practice unknown to the teacher, constituting new knowledge introduced by the students. This stands out as unusual in the series, exemplifying the ongoing negotiation of power relations between adults and students in pedagogical practices enacted on public radio. However, it also indicates how notions of equal citizenship were formulated and acted out in ways hitherto not considered in research into citizenship 
or education. As demonstrated in this section, issues of generation were related to those of gender. The next section will focus on gender.

\section{CHALLENGING GENDER STEREOTYPES}

In Olof Berg's Among sacks of fertilizer and sacks of seed in a farmers' association (1935), a program about the role of farmers' associations, a male teacher set the scene. He explained to the listeners that he was standing outside a specific farmers' association waiting for a class to arrive for a visit. Over the past few days, he said, they had been studying how to run an efficient "modern farm." According to the teacher, one boy, Ragnar, had suggested that they visit a farmers' association, specifically, the one the boy's father headed. The teacher then described the boy as the initiative taker, in terms of both organizing the visit outside school, and thus into society, and of producing the broadcast himself. Moreover, the teacher positioned the boy as a kind of expert, saying that he was "familiar with everything here, because he was already his father's right hand.” The teacher had previously assigned the boy the task of telling how the association had been organized since its inception. The teacher then described the building they were about to enter, emphasizing the sense that both the listeners and participants in the broadcast were taking part in an authentic, real-time event. When the children arrived, they said "good day" and the dialogue started. The dialogue involved the teacher, the abovementioned boy (Ragnar), a girl (Lisa), and miscellaneous students. One key aspect was that this enacted pedagogical practice took place not in school, but out in society.

As mentioned above, the teacher explicitly positioned Ragnar as an insider in this educational—and societal—situation. Such a position was also created by the conversational techniques used. When the boy and girl spoke, they assumed different positions: the boy was answering questions while the girl posed them, as exemplified in the script below. The teacher had given a rather technical description of different fertilizers and their effects when Lisa said:

\section{Script 4.}

LISA: How beautiful that label on the sacks is! A cluster of grain stalks with a garland made of straw around it. Could we make a drawing of it?

TEACHER: You can do that. One of the letters [on the sack] tells us that the superphosphate was produced here in Sweden. There are several factories in our country that produce superphosphate. Yes, and here we 
have a couple of sacks of Thomas phosphate. As you can see from the address, this one comes from

Domnarvet [a factory in Sweden]. What is it about Domnarvet and artificial fertilizer?

RAGNAR: Well, Thomas phosphate is a by-product of iron production.

TEACHER: And we also have potassium nitrate. Right now there are only two sacks of potassium nitrate here. That is fortunate, though, because the price of potassium nitrate will probably fall next season. Well here are some more sacks of potassium nitrate, and one is carbon dioxide saltpeter.

LISA: What is in this sack, the one with "gardening fertilizer" written on it?

TEACHER: I understand that you're interested in that Lisa, since you're so good at kitchen gardening. ${ }^{35}$

As indicated by his answers in the script, the boy stood out as the one with knowledge and personal experience of the farmers' association the school class was visiting and of farming in general. On the other hand, the girl's position was one of being uninformed about "modern farming."

However, there was also a difference in what the children related to. The boy was referring to more technical aspects of farming, at that time part, of a discourse on how to modernize the farming sector. This program, like others, stressed that farming also required theoretical skills, such as knowledge of fertilizers and economics, in addition to more traditional hands-on practices. In other school broadcasts, "modern" farmers were referred to as "entrepreneurs" who ran firms just like others did. ${ }^{36}$ The notion of "modern farming" was brought up as a business for men. Lisa, on the other hand, was related to kitchen gardening, i.e., an important but more traditional activity handled near home by women. Her comment that the label was beautiful, together with her initiative to start drawing, related her, the girl, to esthetic values. Unlike the boy, she was also explicitly described as unfamiliar with fertilizers, even though they were meant for the garden.

The boy and girl played different gender roles in this discursive practice. Moreover, the gender specificities put into practice in the talk-in-interaction were visualized in the instruction manual all schoolchildren were supposed to have in front of them when listening to the broadcasts. Photographs depicted a girl in a kitchen garden near a home and a boy participating in a "crop experiment" in an open field. In making this contrast, the manual positioned the children in different gender roles in terms of both the subjects they were related to - verbally and visually-and how they posed questions and gave answers in the broadcast. In the broadcast, and in the simulated pedagogical 
situation, the girl was given an apparently weak position. However, if one considers that women at this time generally had no access to the public sphere of radio or to farmers' associations, her position could be interpreted as strong. She was given access to spheres of society hitherto occupied exclusively by men, and as such served as a role model for the girls and boys listening to the program.

\section{GENDERED STUDENT POSITIONS}

Besides the two broadcasts already mentioned, with Ingvall and Ann-Marie, and with Ebba and Märta, respectively, yet another program opened with a dialogue between peers. In Small bad habits—big money (1935) (producer unknown), the plot was about one boy's lack of thrift, and the outcome was that he did not have enough money to pay his membership fee in a youth organization. The program aimed to teach him — and supposedly all listening students (and adults) — how to make a budget and thereby become aware of expenses and incomes. Interestingly, except for smoking, all the youth leisure activities were treated with respect by the adult male, Mr Andersson, on the program. Going to the cinema, drinking coffee, buying magazines or pastries were never condemned by the adult, though the youths themselves were quite judgmental in their dialogue. This dialogue between peers was generally characterized by statements, but in this case also driven by conflict between the sexes. Script 5 below shows how referring to specific activities and attributes gendered the girl and the boys. Note that parts of the dialogue, shown here in parentheses, were edited out before broadcast; the head of the school radio section probably made these deletions (and it is unclear whether they were actually broadcast or not). Also note the sound effects marked in the text. Two boys and one girl participate in the dialogue:

\section{Script 5.}

ERIK: You are for sure!

MARGIT: But at least I don't smell of tobacco as you do.

ERIK: Yes, but I don't smell of perfume as you do. And I don't put on make-up as you do. Look she is blushing!

MARGIT: I don't care about you at all. (If I put make up on, I'm not doing it for your sake. Stupid Erik.)

ERIK: Ha, ha, you're doing it for Kalle's sake then! (You're putting on make-up for Kalle's sake!)

MARGIT: No, I'm not ... 
ERIK: Ha, ha, look, the girl is blushing.

KALLE: Get lost!

ERIK: (Yes, I'll leave these small lovebirds alone). [Opens the door.] Goodbye, all of you. (Now little Margit may take a moving farewell of little Kalle.)

KALLE: Watch out!

ERIK: Ha, ha, ha, ha. [The door slams.]

KALLE: That boy will never be anything but stupid.

MARGIT: He's not at all stupid. You're the stupid one, since you're leaving the team. Here comes Mr.

Andersson. Come on, let's go indoors. You can borrow 25 cents from me.

KALLE: Nooo. ${ }^{37}$

The teasing tone between the peers was created by means of references to positive and negative gender attributes. The attributes appeared embarrassing, probably because they marked the transition from an asexual child identity to gendered adult behavior; the girl put on make-up and blushed, while the boys were antagonists and smelled bad. The script shows how both the girl and boys used derogatory descriptions of each other, all of which referred to socially constructed gender roles. Margit was the sole representative of her gender, but she never hesitated to get back at or verbally assault the boys. She was portrayed as a strong girl who could stand up for herself. When the boys tried to make her an ally, she replied by criticizing the one who sought her support. She stood out as provoking, self-assured, and critical. Thus, the male producer placed a female character in a strong position, allowing her either to attack the boys or refuse their invitations. The boys were described as antagonists fighting for the girl's attention. The boys were thus placed in weaker positions than the girl's - unexpected, as this was a public medium then dominated by male producers and male voices.

Later in the program, this was emphasized even more strongly, when the girl was portrayed as the competent child, helping the Mr Andersson make a budget and count, and, in the end, persuading Kalle to stay in the youth organization. In Sweden, women were practically excluded from public radio until the early 1940 s, a fact that made the girl's performance even more interesting. It seems plausible to interpret this as exemplifying the ongoing negotiation between various male identities in the 1920 s and $1930 \mathrm{~s},{ }^{38}$ here performed on public radio by children. The various male 
identities were related to gender equality issues, such as women's rights to state employment and to be family breadwinners. It seems plausible, then, to include School Radio as one forum for these negotiations.

The present analysis of dialogues between peers makes two things clear. First, dialogues involving both boys and girls were characterized by conflicts that could not be solved without adult help. Moreover, these children were performing heterosexual gendered identities (see examples 1, 4, and 5). Second, the broadcast involving same-sex peers was characterized by collaboration and joint effort, and gender was never made an explicit issue. The girls solved problems together and did not need adult help, and they did not make gender an issue; in same-sex relationships, gender-specific behaviors were not brought up explicitly (see scripts 2 and 3).

In forming a peer group dependent on adults, and at the same time gendered and in conflict, the children were arguably placed in a weaker position than the adults. The covert message was that children, as a group, were unable to challenge adult power. However, as the scripts singled out here demonstrate, a child could occasionally be allied to an adult, or, if children were in same-sex relationships, were able to solve problems together. These examples- together with the fact that children participated as representatives of active citizens exploring hitherto unseen sectors of society on radio broadcasts - must be regarded as part of a progressive strategy aimed at increasing equality between adults and children. The children were portrayed as both receptive to and as the ideal products of pedagogical ideals, while being framed as radical and as part of the new education and the new democratic societal order. However, not all teachers welcomed these new portrayals of children, new media, and new notions of citizenship. In the periodicals for secondary school teachers, opposing voices referred to School Radio as a threat to "true knowledge."

\section{CONCLUSION}

As demonstrated here, in the 1930s, Swedish citizens were not only made part of the welfare project through expert scientific or professional descriptions and interpretations of how citizens ought to behave or feel, as has been claimed in earlier research. ${ }^{39}$ Studying dialogues created as everyday school events involving the participation of adults and children exposes the complex interrelationship between continuity and change in times past. This use of dialogues and dramatizations of everyday 
school practices in a public medium exemplifies the role of documentaries in forming and distributing new education and citizenship. The practices indicate how citizens and citizens in the making, such as teachers and students, respectively, were themselves performing — as ordinary people and in demotic speech—what it meant to be active. Being active meant being a learning subject, interested in societal milieus, technological improvements, farmers' associations, or youth organizations, and communicating with others in public dialogue. In gender terms, it meant giving boys and girls access to all parts of society, particularly by making girls portray themselves as ideal students in modern media. In generational terms, it meant both keeping adults in control and empowering students, particularly girls.

In School Radio, students, teachers and other adults interacted in places outside of school, negotiating the meaning and understanding of what was needed and desired when participating in society in ways not present in other contemporary broadcasts on the Swedish Radio. The starting point was taken in public education and in the public media and it delivered factual practices describing how interaction between generations and different gender roles could work. Moreover, the radio broadcast showed how children—-student boys and girls—-were given factual subject positions as citizens, a position making it possible to understand oneself as a subject, to dare to make choices, to realize that change is possible, and to trust society and societal solutions. ${ }^{40}$ In this, the programs empowered the young and inspired them to engage in society, even though they were still in inferior positions as citizens in the making.

Taking School Radio as an exemplar, the new medium of radio seems to have been an important mediator of ideological standpoints, using ordinary people and a media format explicitly striving to dissolve the boundaries between the represented and the real as a way to attract and motivate its audience. This meant that, at that time, children who listened to educational programs on the radio, discussed them, and did assignments based on them encountered progressive, modern views of society. The inclusion of ordinary people — and particularly children in school—was not driven by commercial interests, but instead by cultural, educational, and political rationales.

According to Mark Jans, citizen participation today positions children and adults in an educational discourse, making both adults and children responsible for learning to be citizens. ${ }^{41}$ The 
school radio broadcasts analyzed here could be taken as exemplifying early forms of such ideals. They can also be interpreted as forerunners of factual examples of what is needed today, namely, the creation of interdependence between children and adults in an educational setting that fosters citizen participation.

${ }^{1}$ Paul Arthur, "Jargons of Authenticity (Three American moments)," in Theorizing Documentary, ed. Michael Renov (London \& New York: Routledge, 1993), 108-134; Brian Winston, "The Documentary Film as Scientific Inscription," in Theorizing Documentary, ed. Michael Renov (London \& New York: Routledge, 1993), 37-51.

${ }^{2}$ David Hogarth, “The Other Documentary Tradition: Early Radio Documentaries in Canada," Historical Journal of Film, Radio and Television 21 (2001): 123-135.

${ }^{3}$ Hogarth, "The Other Documentary Tradition," 124.

${ }^{4}$ Maija Runcis and Bengt Sandin, Neither Fish nor Fowl: Educational Broadcasting in Sweden 1930-2000 (Lund: Nordic Academic Press, 2010), 27-29.

${ }^{5}$ Runcis and Sandin, Neither Fish nor Fowl, 31-34, 39.

${ }^{6}$ Runcis and Sandin, Neither Fish nor Fowl, 28.

${ }^{7}$ SOU [Swedish Government Official Reports] 1935:10, Utredning och förslag angående rundradion i Sverige.

${ }^{8}$ Runcis and Sandin, Neither Fish nor Fowl, 34-35. This meant that educational broadcasting had initially been financed by the state.

${ }^{9}$ Benedict Anderson, Imagined Communities: Reflections on the Origin and Spread of Nationalism (London: Verso, 2006); Anne-Li Lindgren, “Att ha barn med är en god sak”: Barn, medier och medborgarskap under 1930-talet (Ph.D. diss., Linköping University, 1999).

${ }^{10}$ Anne-Li Lindgren, "Radio," in Encyclopedia of Children and Youth in History and Society, ed. Paula S. Fass (New York: Macmillan Reference USA, 2003), 707-709; Lindgren, “Att ha barn med är en god sak,” 37.

${ }^{11}$ Lindgren, "Radio," 707-709.

${ }^{12}$ Lindgren, "Att ha barn med är en god sak," 45-47; Runcis and Sandin, Neither Fish nor Fowl, 32-33.

${ }^{13}$ Lindgren, "Radio," 707-709.

${ }^{14}$ Larry Cuban, Teachers and Machines: The Classroom use of Technology since 1920 (New York and London: Teachers College Press, 1986).

${ }^{15}$ Runcis and Sandin, Neither Fish nor Fowl, 39, 41-42; Karin Nordberg, Folkhemmets röst: radio som folkbildare 1925-1950 (Ph.D. diss., Stockholm: Symposion, 1998), 34, 37. See also references in footnote 39. 
${ }^{16}$ The producers singled out here were known in the teaching community, since they appeared in teachers' periodicals, but their names are not in the history books or in any other public record.

${ }^{17}$ Graeme Turner, Ordinary People and the Media: The Demotic Turn (London: SAGE, 2010), 2-3, 6 .

${ }^{18}$ Stuart Ewen, Captains of Consciousness: Advertising and the Social Roots of the Consumer Culture (New York: Basic Books, 1976/2001), 31, 179, 219; David Hendy, "BBC Radio Four and conflicts over spoken English in the 1970s," Media History 12, no. 3 (2006): 273-289; Hogarth, "The Other Documentary Tradition," 123-135; Turner, Ordinary People and the Media, 6.

${ }^{19}$ Runcis and Sandin, Neither Fish nor Fowl, 26.

${ }^{20}$ Runcis and Sandin, Neither Fish nor Fowl, 13.

${ }^{21}$ Cf. Hugh Cunningham, Children of the Poor: Representations of Childhood since the Seventeenth Century (Oxford: Blackwell, 1992); Harry Hendrick, Children, Childhood and English Society 1880-1990 (Cambridge: Cambridge University Press, 1997).

${ }^{22}$ Fairclough, Discourse and Social Change (Cambridge: Polity Press, 1992), 4, 71.

${ }^{23}$ Lindgren, "Att ha barn med är en god sak," 40-41.

${ }^{24}$ Lindgren, "Att ha barn med är en god sak," 44-50.

${ }^{25}$ Hendy, "BBC Radio Four,” 274-275. In BBC's Radio Four, this was disputed still in the early 1970s, Hendy, "BBC Radio Four," 278-279.

${ }^{26}$ Fairclough, Discourse and Social Change , 58, 60-61.

${ }^{27}$ Fairclough, Discourse and Social Change, 55, 60, 83, 138-149, 152-157.

${ }^{28}$ The calendar-our most widely distributed reference book (Lorentz Larsson), 21 February 1935, Researchand Archive Centre, Stockholm, Sweden, Skolradions arkiv, File B60 (hereafter SRF).

${ }^{29}$ John Dewey, The School and Society (Chicago: University of Chicago Press, 1915).

${ }^{30}$ The tone of voice (Ebba Berggren), 14 March 1935, SRF.

${ }^{31}$ For example, a program about constructing new roads was produced as a dialogue between a male teacher and a road construction engineer. In it, the teacher produced seven questions, no answers, and 13 statements, while the engineer produced no questions, seven answers, and 12 statements; Among blasts and road builders (Producer unknown), 18 January 1935, SRF.

${ }^{32}$ The tone of voice (Ebba Berggren), 14 March 1935, SRF.

${ }^{33}$ How to use the telephone book (Karin Skerfe), 21 March 1935, SRF.

${ }^{34}$ How to use the telephone book (Karin Skerfe), 21 March 1935, SRF. 
${ }^{35}$ Among sacks of fertilizer and sacks of seed in a farmers' association (Olof Berg), 9 January 1935, SRF.

${ }^{36}$ Lindgren, "Att ha barn med är en god sak," 213.

${ }^{37}$ Small bad habits_-big money (Unknown), 23 January 1935, SRF.

${ }^{38}$ Renée Frangeur, "Social Democrats and the Women Question in Sweden: A History of Contradiction," in Women and Socialism/Socialism and Women, eds. Helmut Gruber and Pamela Graves (London \& New York: Routledge, 1998).

${ }^{39}$ Yvonne Hirdman, "Social Engineering and the Woman Question: Sweden in the Thirties," in Swedish Social Democracy: A Model in Transition, eds. Clement Wallace and Rianne Mahone (Toronto: Canadian Scholar's Press), 65-81; Bo Rothstein, Vad bör staten göra? Om välfärdsstatens moraliska och politiska logik (Stockholm: SNS förlag). See also footnote 15.

${ }^{40}$ Birte Siim, Gender and Citizenship: Politics and Agency in France, Britain and Denmark (Cambridge: Cambridge University Press, 2000); Kathleen Canning and Sonya O. Rose, eds., Gender, Citizenship and Subjectivities (Oxford: Blackwell, 2002).

${ }^{41}$ Mark Jans, "Children as Citizens: Towards a Contemporary Notion of Child Participation," Childhood 11 (2004): 27-44.

Table 1. Questions, answers and other utterances in five school radio broadcasts in 1935.

\begin{tabular}{|c|c|c|c|c|c|}
\hline Broadcasts & Characters & Questions & Answers & $\begin{array}{l}\text { Other } \\
\text { utterances }\end{array}$ & Total \\
\hline \multirow{4}{*}{$\begin{array}{l}\text { Among sacks of fertilizers, } \\
\text { January } 23\end{array}$} & Girl Student & 5 & 2 & 4 & 11 \\
\hline & Boy Student & 0 & 5 & 9 & 14 \\
\hline & Male Teacher & 9 & 5 & 10 & 24 \\
\hline & Other (students) & 0 & 0 & 2 & 2 \\
\hline \multirow{5}{*}{$\begin{array}{l}\text { Small habits - big money, } \\
\text { February } 21\end{array}$} & Girl Student & 3 & 10 & 28 & 41 \\
\hline & $\begin{array}{l}\text { Boy Student } \\
\text { (Kalle) }\end{array}$ & 2 & 31 & 18 & 51 \\
\hline & $\begin{array}{l}\text { Boy Student } \\
\text { (Erik) }\end{array}$ & 4 & 0 & 15 & 19 \\
\hline & $\begin{array}{l}\text { Uncle } \\
\text { Andersson }\end{array}$ & 36 & 3 & 14 & 53 \\
\hline & Other (students) & 0 & 0 & 2 & 2 \\
\hline \multirow[t]{3}{*}{$\begin{array}{l}\text { The Calendar-Our mostly } \\
\text { distributed reference book, } \\
\text { February } 27\end{array}$} & Girl Student & 3 & 17 & 9 & 29 \\
\hline & Boy Student & 2 & 19 & 12 & 33 \\
\hline & Other (student) & 1 & 74 & 2 & 77 \\
\hline
\end{tabular}




\begin{tabular}{|c|c|c|c|c|c|}
\hline \multirow{3}{*}{ The tone of voice, March 14} & Male Teacher & 102 & 0 & 16 & 118 \\
\hline & Girl Student & 13 & 28 & 12 & 53 \\
\hline & $\begin{array}{l}\text { Madame } \\
\text { Berggren }\end{array}$ & 29 & 6 & 17 & 52 \\
\hline \multirow[t]{3}{*}{$\begin{array}{l}\text { How to use the telephone book, } \\
\text { March } 21\end{array}$} & $\begin{array}{l}\text { Girl Student } \\
\text { (Ebba) }\end{array}$ & 8 & 8 & 28 & 44 \\
\hline & $\begin{array}{l}\text { Girl Student } \\
\text { (Märta) }\end{array}$ & 9 & 12 & 23 & 44 \\
\hline & Female Teacher & 9 & 0 & 4 & 13 \\
\hline Total & & 265 & 245 & 273 & 783 \\
\hline
\end{tabular}

